\title{
PERUMUSAN DIAGNOSA KEPERAWATAN DALAM \\ MEMBERIKAN ASUHAN KEPERAWATAN PADA PASIEN
}

\author{
Rahel Juliana Benedikta Berutu \\ E-mail : beruturahel1507@ gmail.com
}

\section{LATAR BELAKANG}

Diagnosa keperawatan adalah termasuk contoh sebuah konsep. Dimana diagnosa keperawatan merupakan interpretasi data secara ilmiah, memadu unutuk membuat rencana, implementasi dan evaluasi praktik Keperawatan. Diagnosa akan membantu perawat untuk merumuskan intervensi yang tepat agar bisa menyelesaikan masalah pasien.

Diagnosis Keperawatan merupakan keputusan klinik tentang respon individu, keluarga dan masyarakat tentang masalah kesehatan aktual atau potensial, dimana berdasarkan pendidikan dan pengalamannya, perawat secara akontabilitas dapat mengidentifikasi dan memberikan intervensi secara pasti untuk menjaga, menurunkan, membatasi, mencegah dan merubah status kesehatan klien. Dewasa ini tak jarang di temukannya kesalahan dalam perumusan diagnose keperawatan, baik oleh mahasiswa kepeerawatan yang sedang melakukan praktik maupun oleh perawat professional.

Diagnosis adalah fase kedua proses keperawatan. Pada fase ini, perawat menggunakan keterampilan berpikir kritis untuk menginterpretasikan data pengkajian dan mengidentifikasi kekuatan serta masalah klien. Kajian ini membahas tentang perumusan diagnosa keperawatan yang bertujuan untuk memberikan informasi terkait tahap diagnosis keperawatan dalam proses keperawatan, memberikan pengetahuan terhadap perawat bagaimana langkah-langkah perumusan diagnosa keperawatan terhadap data-data klien yang sudah dikumpulkan. Kajian ini menggunakan metode kualitatif, metode kualitatif ini bersifat memberikan penjelasan dengan membuat analisis.

Proses pengkajian ini lebih menggunakan landasan teori dengan mengumpulkan data, bereksplorasi bebas yang telah disimpulkan dari berbagai sumber-sumber buku dan jurnal mengenai perumusan diagnosa keperawatan. Hasil yang diharapkan agar perawat mampu untuk berpikir kritis dalam melakukan perumusan diagnosa keperawatan sesuai dengan datadata informasi status kesehatan klien dengan tepat. Pada tahun 1990, NANDA menggunakan definisi kerja resmi diagnosis keperawatan “... penilaian klinis tentang respons individu, keluarga, atau masyarakat terhadap proses hidup/masalah kesehatan aktual dan potensial, Rumusan diagnosis keperawatan dapat berbentuk diagnosis aktual, risiko, sindrom, potensial, dan kemungkinan.

Pada proses keperawatan, setelah melakukan pengkajian, langkah selanjutnya yang dilakukan seorang perawat adalah merumuskan diagnose, agar nantinya seorang perawat dapat melakukan perencanaan dari hasil diagnose yang telah dirumuskan. Salah satu 
kompetensi perawat mampu merumuskan diagnosa keperawatan yang baik dan benar, dimana diagnosa keperawatan merupakan kesimpulan yang dihasilkan dari analisis data, sehingga menghasilkan pernyataan yang jelas, singkat dan pasti tentang masalah pasien.

Tujuan dilakukannya perumusan masalah dalam pengkajian adalah agar dapat dengan mudah untuk menentukan diagnosa pasien.Seorang perawat pada saat menentukan diagnosa keperawatan akan melakukan perumusan diagnosa keprawatan berdasarkan pengalaman atau apa yang sedang di alami oleh klien / pasien.

Alasan untuk merumuskan diagnosa keperawatan setelah menganalisis data pengkajian adalah untuk mengidentifikasi masalah kesehatan yang melibatkan klien dan keluarganya dan untuk memberikan arah asuhan keperawatan.pernyataan diagnosa keperawatan adalah hasil dari proses diagnostik selama perawat menggunakan pemikiran kritis, diagnosa kepearawatan dikembangkan untuk klien,keluarga, atau komunitaas dan mencakup data fisik perkembangan, intelektual, emosi, sosial dan spiritual yang didapapatkan selama pengkajian.

Kata Kunci : Perumusan, Diagnosa Keperawatan, Asuhan Keperawatan, Pasien

\section{METODE}

Metode penulisan yang digunakan dalam penulisan laporan ini adalah literature review. Literature review yang dilakukan berupa telaah pustaka artikel penelitian. Artikel dipublikasikan secara elektronik dan diunduh melalui Google Scholar,science direct, scopus, ebook, dan dari beberapa buku keperawatan.. Kata Kunci yang digunakan yaitu Alat Pelindung Diri (APD), Penyakit akibat kerja, serta Perawat. Kriteria inklusi artikel adalah diterbitkan dari tahun 2012 hingga 2020, dan fulltext. Prosedur pengumpulan data yang digunakan adalah menentukan keyword untuk pencarian literatur yang relevan dengan topik kajian dan melakukan penelusuran mengenai topik relevan.

\section{HASIL}

Jurnal yang berjudul DIAGNOSA KEPERAWATAN SEJAHTERA bertujuan agar perawat melakukan perubahan yang bersifat perilaku agar dapat merumuskan diagnosa keperawatan sejahtera karena penggunaan diagnosa yang berorientasi pada masalah telah lebih dikenal dan dianut oleh para praktisi keperawatan dibandingkan dengan pemilihan diagnosa keperawatan sejahtera yang membutuhkan pengidentifikasian kekuatan klien sebagai salah satu langkah perumusannya. Upaya yang lebih konkrit dapat dilakukan untuk mengembangkan diagnosa keperawatan sejahtera ini melalui praktik langsung di tatanan pelayanan keperawatan yang memfokuskan pelayanannya pada upaya promosi kesehatan klien seperti Puskesmas atau Posyandu, sehingga daftar diagnosa keperawatan sejahtera dapat dikembangkan atau divalidasi pada kondisi aktual di negara kita

Buku yang berjudul Konsep-konsep Dasar dalam Keperawatan Komunitas menyimpulkan bahwa Diagnosa keperawatan di tetapkan berdasarkan analisis dan interpretasi data yang di peroleh dari pengkajian klien. Diagnosa keperawatan memberikan gambaran tentang kesehatan yang nyata (aktual) dan memungkinkan akan terjadi, disana pengambilan keputusannya dapat di lakukan dalam batas wewenang perawat. 
Buku yang berjudul Asuhan Keperawatan pada Pasien menyimpulkan Diagnosa keperawatan yang di rumuskan oleh perawat, di dasarkan dari pengalaman dan pengetahuan guna mencegah, menurunkan dan mengubah status kesehatan klien. Perumusan Diagnosa Keperawatan meliputi beberapa komponen penting yaitu Problem(P), etiologi (E), Sign dan symptom(S). Seorang perawat merumuskan diagnosa keperawatan di dasarkan pada masalah yang di alami klien.

Buku yang berjudul Proses Keperawatan Penerapan Konsep dan Kerangka Kerja menyimpulkan bahwa seorang perawat harus kompeten dalam merumuskan diagnosa keperawatan, untuk merumuskan diagnosa keperawatan yang tepat seorang perawat membutuhkan pengetahuan dan keterampilan, seperti pemahaman kondisi pasien, faktor penyebab, karakteristik kondisi pasien dan kemampuan untuk mengintegrasikan semua informasi untuk membentuk sebuah kesimpulan.

Buku yang berjudul Teori Model Keperawatan menyimpulkan bahwa Penetapan diagnosa keperawatan berdasarkan analisis serta interpretasi data melalui pengkajian keperawatan yang aktual dan kemungkinan terjadi yang di lakukan dalam wewenang perawat.

Sebagai seorang perawat sudah seharusnya mengetahui proses dalam pembuatan diagnose. Dan juga sudah seharusnya sebagai seorang perawat kita mengetahui perbedaan dari diagnose keperawatan dengan diagnose medis sehingga dapat terhindar dari kesalahan yang dapat terjadi. Dengan terhindarnya dari kesalahankesalahan pada saat pembuatan diagnose maka pelayanan yang di akan di berikan kepada klien akan semakin meningkat.

\section{PEMBAHASAN}

Diagnosa keperawatan adalah langkah kedua dari proses keperawatan yang menggambarkan penilaian klinis tentang respon individu, keluarga, kelompok maupun masyarakat terhadap permasalahan kesehatan baik aktual maupun potensial. Dimana perawat mempunyai lisensi dan kompetensi untuk mengtasinya.

Diagnosa keperawatan merupakan hasil perumusan berdasarkan respon dari individu, keluarga, dan masyarakat mengenai masalah-masalah kesehatan yang aktual dan potensial yang dialami oleh klien. Diagnosa Keperawatan yang di rumuskan oleh perawat, di dasarkan dari pengalaman dan pengetahuan guna mencegah, menurunkan dan mengubah keadaan status kesehatan klien.

Penetapan diagnosa keperawatan berdasarkan analisis serta interpretasi data melalui pengkajian keperawatan yang aktual dan kemungkinan terjadi yang di lakukan dalam wewenang perawat. Dapat di simpulkan bahwa seorang perawat harus kompeten dalam merumuskan diagnosa keperawatan, untuk merumuskan diagnosa keperawatan yang tepat seorang perawat membutuhkan pengetahuan dan keterampilan, seperti pemahaman kondisi pasien, faktor penyebab, karakteristik kondisi pasien dan kemampuan untuk mengintegrasikan semua informasi untuk membentuk sebuah kesimpulan.

Diagnosa keperawatan adalah termasuk contoh sebuah konsep. Dimana diagnosa keperawatan merupakan interpretasi data secara ilmiah, memandu untuk membuat rencana implementasi dan evaluasi praktik keperawatan. Diagnosa Keperawatan akan membantu perawat untuk merumuskan intervensi yang tepat agar bisa menyelesaikan masalah pasien. 
Diagnosa keperawatan, konsep diagnosa dirancang untuk pola penghargaan. Diagnosa keperawatan untuk situasi perawatan kesehatan pasien/ keluarga meliputi nama diagnosa dan faktor-faktor berhubungan yang mempengaruhi awal gejala/ pemeliharaan dari suatu diagnosa aktual atau nama diagnosa dan faktor-faktor resiko tinggi.

Dalam menentukan diagnosa keperawatan ada beberapa proses keperawatan yang di lakukan oleh perawat yaitu Pengkajian, diagnosa keperawatan, intervensi dan implementasi dan evaluasi.

Ada tiga komponen yang esensial dalam suatu diagnosa keperawatan yang telah dirujuk sebagai bentuk PES ( Gordon, 1987 ). " $\mathrm{P}$ “ diidendtifikasi sebagai masalah/ problem kesehatan, "E" menunjukan etiologi/ penyebab dari problem, dan "S" menggambarkan sekelompok tanda dan gejala, atau apa yang dikenal sebagai " batasan karakteristik" ketiga bagian ini dipadukan dalam suatu pernyataan dengan menggunakan " yang berhubungan dengan." Kemudian diagnosa-diagnosa tersebut dituliskan dengan cara berikut : Problem “ yang berhubungan dengan " etiologi” dibuktikanoleh"tanda-tanda dan gejalagejala(batasankarakteristik).

Rumusan diagnosis keperawatan mengandung tiga komponen utama, yaitu :

1. Problem (P/masalah)

Merupakan gambaran keadaan klien dimana tindakan keperawatan dapat diberikan. Masalah adalah kesenjangan atau penyimpangan dari keadaan normal yang seharusnya tidak terjadi.

Tujuan : menjelaskan status kesehatan klien atau masalah kesehatan klien secara jelas dan sesingkat mungkin. Diagnosis keperawatan disusun dengan menggunakan standart yang telah disepakati (NANDA, Doengoes, Carpenito, Gordon, dll), supaya :

a. Perawat dapat berkomunikasi dengan istilah yang dimengerti secara umum

b. Memfasilitasi dan mengakses diagnosa keperawatan

c. Sebagai metode untuk mengidentifikasi perbedaan masalah keperawatan dengan masalah medis

d. Meningkatkan kerjasama perawat dalam mendefinisikan diagnosis dari data pengkajian dan intervensi keperawatan, sehingga dapat meningkatkan mutu asuhan keperawatan.

Problem dapat diidentifikasikan sebagai respons manusia terhadap masalah-masalah kesehatan yang aktual atau potensial sesuai dengan data-data yang didapat dari pengkajian yang dilakukan oleh perawat. Etiologi ditunjukan melalui pengalaman-pengalaman individu yang telah lalu, pengaruh genetika, faktor-faktor lingkungan yang ada saat ini, atau perubahan-perubahan patofisiologis. Tanda dan gejala menggambarkan apa yang pasien katakan dan apa yang diobservasi oleh perawat yang mengidentifikasikan adanya masalah tertentu.

Informasi yang ditampilkan pada setiap diagnosa keperawatan mencakup hal-hal berikut :

1. Defenisi. Merujuk kepada defenisi NANDA yang digunakan pada diagnosa -diagnosa keperawatan yang telah ditetapkan tersebut.

2. Kemungkinan Etiologi ("yang berhubungan dengan"). Bagian ini menyatakan penyebabpenyebab yang mungkin untuk masalah yang telah diidentifikasi. Yang tidak dinyakatakan 
oleh NANDA diberi tanda kurung [ ]. Faktor yang berhubungan/ Risiko diberikan untuk diagnosa yang beresiko tinggi.

3. Batasan karakteristik ("dibuktikan oleh"). Bagian ini mencakup tanda dan gejala yang cukup jelas untuk mengindikasi keberadaan suatu masalah. Sekali lagi seperti pada defenisi dan etiologi. Yang tidak dinyatakan oleh NANDA diberi tanda kurung .

4. Sasaran / Tujuan. Pernyataan -pernyataan ini ditulis sesuai dengan objektif perilaku pasien. Sasaran/ tujuan ini harus dapat diukur, merupakan tujuan jangka panjang dan pendek, untuk digunakan dalam mengevaluasi keefektifan intervensi keperawatan dalam mengatasi masalah yang telah diidentifikasi. Mungkin akan ada lebih dari satu tujuan jangka pendek, dan mungkin merupakan "batu loncatan" untuk memenuhi tujuan jangka panjang.

5. Intervensi dengan Rasional Tertentu. Hanya intervensi-intervensi yang sesuai untuk bagian diagnosa yang ditampilkan Rasional-rasional yang digunakan untuk intervensi mencakup memberikan klarifikasi pengetahuan keperawatan dasar dan untuk membantu dalam menseleksi intervensi-intervensi yang sesuai untuk diri pasien.

6. Hasil Pasien yang Diharapkan/ Kriteria Pulang. Perubahan perilaku sesuai dengan kesiapan pasien untuk pulang yang mungkin untuk dievaluasi.

7. Informasi Obat - obatan. Informasi ini mencakup implikasi keperawatan, menyertai babbab yang mana tiap klarifikasinya sesuai.

\section{Etiologi (E/penyebab)}

Keadaan ini menunjukkan penyebab keadaan atau masalah kesehatan yang memberikan arah terhadap terapi keperawatan. Penyebabnya meliputi : perilaku, lingkungan, interaksi antara perilaku dan lingkungan.

Unsur-unsur dalam identifikasi etiologi :

a. Patofisiologi penyakit : adalah semua proses penyakit, akut atau kronis yang dapat menyebabkan / mendukung masalah.

b. Situasional : personal dan lingkungan (kurang pengetahuan, isolasi sosial, dll)

c. Medikasi (berhubungan dengan program pengobatan/perawatan) : keterbatasan institusi atau rumah sakit, sehingga tidak mampu memberikan perawatan.

d. Maturasional :

Adolesent : ketergantungan dalam kelompok

Young Adult : menikah, hamil, menjadi orang tua

Dewasa : tekanan karier, tanda-tanda pubertas.

\section{Sign \& symptom (S/tanda \& gejala),}

Sign \& symptom adalah ciri, tanda atau gejala, yang merupakan informasi yang diperlukan untuk merumuskan diagnosis keperawatan. Jadi rumus diagnosis keperawatan adalah : PE / PES. Persyaratan Penyusunan Diagnosis Keperawatan. Perumusan harus jelas dan singkat dari respon klien terhadap situasi atau keadaan yang dihadapi

1. Spesifi dan akurat (pasti)

2. Dapat merupakan pernyataan dari penyebab

3. Memberikan arahan pada asuhan keperawatan 
4. Dapat dilaksanakan oleh perawat pencerminan keadaan kesehatan klien

Dalam merumuskan diagnosa komponen yang harus diperhatikan adalah problem, etiologi, dan sign atau symptom dengan syaratnya, yakni" perumusan harus jelas dan singkat dari respon klien terhadap situasi ataukeadaan yang dihadapi, spesifik dan akurat (pasti), dapat merupakan pernyataan dari penyebab, memberikan arahan pada asuhan keperawatan, dapat dilaksanakan oleh perawat

Mencerminan keadaan kesehatan klienProses yang terdapat dalam merumuskan diagnosa yaitu klasifikasi dan analisis data, mengindentifikasi masalah klien,memvalidasi diagnosis keperawatan, dan menyusun diagnosis keperawatan sesuai dengan prioritasnya

Ada beberapa hal-hal yang perlu di perhatikan dalam menentukan diagnosa keperawatan yaitu berorientasi kepada klien, keluarga dan masyarakat, bersifat aktual atau potensial, dapat diatasi dengan intervensi keperawatan, dan menyatakan masalah kesehatan individu, keluarga dan masyarakat, serta faktor-faktor penyebab timbulnya masalah tersebut.

Ada beberapa alasan diagnosa keperawatan yaitu memberikan asuhan keperawatan secara komprehensif, memberikan kesatuan bahasa dalam profesi keperawatan, meningkatkan komunikasi antar sejawat dan profesi kesehatan lainnya, membantu merumuskan hasil yang diharapkan / tujuan yang tepat dalam menjamin mutu asuhan keperawatan, sehingga pemilihan intervensi lebih akurat dan menjadi pedoman dalam melakukan evaluasi, menciptakan standar praktik keperawatan dan memberikan dasar peningkatan kualitas pelayanan keperawatan.

Menyusun prioritas sebuah diagnosa keperawatan hendaknya diurutkan sesuai dengan keadaan dan kebutuhan utama klien, dengan kategori pertama berdasarkan tingkat Kegawatan artinya keadaan yang mengancam kehidupan., keadaan yang tidak gawat dan tidak mengancam kehidupan dan persepsi tentang kesehatan dan keperawatan dan yang kedua berdasarkan Kebutuhan maslow,yaitu Kebutuhan fisiologis,kebutuhan keamanan dan keselamatan,kebutuhan mencintai dan dicintai,kebutuhan harga diri dan kebutuhan aktualisasi diri.

\section{PENUTUP}

\section{Kesimpulan}

Diagnosa keperawatan adalah langkah kedua dari proses keperawatan yang menggambarkan penilaian klinis tentang respon individu, keluarga, kelompok maupun masyarakat terhadap permasalahan kesehatan baik aktual maupun potensial. Dimana perawat mempunyai lisensi dan kompetensi untuk mengtasinya. Diagnosa keperawatan merupakan hasil perumusan berdasarkan respon dari individu, keluarga, dan masyarakat mengenai masalah-masalah kesehatan yang aktual dan potensial yang dialami oleh klien. Diagnosa Keperawatan yang di rumuskan oleh perawat, di dasarkan dari pengalaman dan pengetahuan guna mencegah, menurunkan dan mengubah keadaan status kesehatan klien.

Dalam merumuskan diagnosa komponen yang harus diperhatikan adalah problem, etiologi, dan sign atau symptom dengan syaratnya, yakni" perumusan harus jelas dan singkat 
dari respon klien terhadap situasi ataukeadaan yang dihadapi, spesifik dan akurat (pasti), dapat merupakan pernyataan dari penyebab, memberikan arahan pada asuhan keperawatan, dapat dilaksanakan oleh perawat dan mencerminan keadaan kesehatan klien. Proses yang terdapat dalam merumuskan diagnosa yaitu klasifikasi dan analisis data, mengindentifikasi masalah klien,memvalidasi diagnosis keperawatan, dan menyusun diagnosis keperawatan sesuai dengan prioritasnya

\section{Saran}

Penulis menyarankan agar perawat dapat berkerja profesional dalam menjalankan tugas dan kewajiban sebagai seorang perawat yang ideal dan bertanggung jawab, dengan merumuskan diagnosa keperawatan sesuai dengan perumusan diagnosa keperawatan yang tepat. Sehingga pasien dapat merasakan kepuasan atas asuhan keperawatan yang diberikan.

\section{DAFTAR PUSTAKA}

Agung,M.(2019). Konsep-Konsep Dasar Dalam Keperawatan Komunitas. Yogyakarta : PENERBIT DEEPUBLISH (Grup Penerbitan CV BUDI UTAMA)

Aini,N.(2018). Teori Model Keperawatan. Malang : Penerbit Universitas Muhammadiyah Malang.

Apriyani,H.(2015).IDENTIFIKASI DIAGNOSIS KEPERAWATAN PADA PASIEN DI RUANG PARU SEBUAH RUMAH SAKIT. Jurnal Ilmiah Keperawatan Sai Betik Penerbit Jurusan Keperawatan Poltekkes Kemenkes Tanjungkarang Bandar Lampung Indonesia Vol 11 No 1.

Bararah, Taqiyyah. (2013). Asuhan Keperawatan Panduan Lengkap Menjadi Perawat Profesional Jilid 1. Jakarta: Prestasi Pustaka.

Dermawan, D. (2012). Proses Keperawatan Penerapan Konsep dan Kerangka Kerja. Yogyakarta: Gosyen Publishing

Hidayah, N. (2014). Manajemen Model Asuhan Keperawatan Profesional (MAKP) Tim Dalam Peningkatan Kepuasan Pasien di Rumah Sakit. Jurnal Kesehatan, 7, 410-426.

Irman,O., Nelista,Y., Maria,Y.(2020). Asuhan Keperawatan Pada Pasien Sindrom Koroner Akut. Pasuruan, Jawa Timur : CV.Penerbit Qiara Media.

Nanda International,.(2018). Nursing Diagnosa: Defenition \& classification 2018-2020, Penerbit Buku Kedokteran: EGC

Sari, D. W. P., Issroviatiningrum, R., \& Soraya, R. S. (2019). Hubungan antara Pelayanan Keperawatan Berbasis Spiritual dengan Kepuasan Kerja Perawat. Jurnal Riset Kesehatan, $8(1), 53-59$ 
Simamora, R. H., Bukit, E., Purba, J. M., \&Siahaan, J. (2017). Penguatan kinerja perawat dalam pemberian asuhan keperawatan melalui pelatihan ronde keperawatan di rumah sakit royal prima medan. Jurnal pengabdian kepada masyarakat, 23(2), 300-304.

Simamora, R. H. (2019). Socialization of Information Technology Utilization and Knowledge of Information System Effectiveness at Hospital Nurses in Medan, North Sumatra. Editorial Preface From the Desk of Managing Editor..., 10(9).

Wulandari,P., Krianto,T., Priwahyuni,Y .(2016).FAKTOR-FAKTOR YANG BERHUBUNGAN DENGAN PENDOKUMENTASIAN ASUHAN KEPERAWATAN DI RUMAH SAKIT JIWA.NERS JURNAL KEPERAWATAN,Volume 12, No.2, Oktober 2016, (Hal.131-142) 